\title{
A Synchronized Grid Integrated Three-Phase Inverter with a Renewable Source for Power Sharing
}

\author{
Zuhair Alqarni, Johnson A. Asumadu \\ Department of Electrical and Computer Engineering, Western Michigan University, Kalamazoo, MI, USA \\ Email: zuhairahmeds.alqarni@wmich.edu
}

How to cite this paper: Alqarni, Z. and Asumadu, J.A. (2020) A Synchronized Grid Integrated Three-Phase Inverter with a Renewable Source for Power Sharing. Journal of Power and Energy Engineering, 8, 88-101. https://doi.org/10.4236/jpee.2020.83006

Received: March 5, 2020

Accepted: March 28, 2020

Published: March 31, 2020

Copyright () 2020 by author(s) and Scientific Research Publishing Inc. This work is licensed under the Creative Commons Attribution International License (CC BY 4.0).

http://creativecommons.org/licenses/by/4.0/

\section{(c) (i) Open Access}

\begin{abstract}
In this paper, a three-phase inverter with renewable source input is integrated into a grid in synchronization for power sharing by load. In previous topologies, the DC source connected inverter is not synchronized to the grid which causes harmonics and voltage distortions damaging the load and the source. In order to ensure power sharing by the load from the inverter and the grid, the inverter needs to be operated in synchronization to the grid with the same voltage magnitude, frequency and phase as that of the grid voltage. In this paper, the complete power from the load is shared by the three-phase grid and the three-phase inverter module reducing the consumption from the conventional grid. This is achieved using the PLL for the reference angular frequency generation with feedback from grid voltage and is connected to the sinusoidal PWM generator. The PLL is used to generate unit vector template reference signals for the signal generator operating the six-switch inverter. The inverter and grid are interconnected through LC filter for the reduction of harmonics. The power sharing, voltage, and current graphs with THD analysis are analyzed with the help of the MATLAB software.
\end{abstract}

\section{Keywords}

PLL (Phase Locked Loop), LC (Inductor Capacitor) Filter, PWM (Pulse Width Modulation), THD (Total Harmonic Distortion), MATLAB (Matrix Laboratory)

\section{Introduction}

In recent years, there is huge development of renewable energy power generation to reduce global warming due to generations of environmentally hazardous gases from the conventional way of generation. The conventional way of gene- 
rating power is by thermal power plants (which include coal plants, nuclear power plants etc.), or utilizing diesel generators which cause smoke and fumes resulting in increasing the earth's temperature. This continuation of generating power using these resources may lead to further destruction of the environment and make it uninhabitable for humans. To ensure avoiding such catastrophe, the conventional way of generating power needs to be replaced with renewable power generation. Renewable sources like solar irradiation, wind, tidal waves, biogas, and chemical fusion [1] [2] [3] [4] can be used which do not generate fumes or gases during generation. The replacement of conventional sources with these units decreases the pollution in the environment and is less hazardous for humans to survive.

The PVA (Photo Voltaic Array) is used for power generation from solar irradiation, turbines are used for power generation from wind [3] [4] and tidal waves, biogas can be used for thermal power generation with steam generation, fuel cells are the sources which use chemical fusion reaction for generating power [2]. As a comparison of all these sources, solar power generation using PV panels is easier, cheaper, and lower maintenance. The power generated from this source is DC which needs to be converted to AC in order to operate the loads. The conversion can be single-phase or three-phase AC. Other sources like wind farms, tidal power plants, and biogas plants generate power directly as $\mathrm{AC}$ which can be connected directly to load without any conversion. Operating these sources in a standalone condition [5] [6] [7] is much easier compared to interconnection with the grid for a parallel power sharing condition [4]. For a parallel operation with the grid, the conversion from DC to AC needs to be synchronized to the grid voltage magnitude, frequency, and phase. For testing the power injection from a DC source (PVA) to the grid in synchronization [8] [9], a simple three-phase test system is considered with a three-phase inverter connected to the grid as given below.

Figure 1 shows test system block diagram, the DC source (PVA) is connected to a DC-DC booster converter for increasing the voltage magnitude to the maximum value of the grid AC voltage because the voltage of the DC source will be of a lower magnitude. The boosted voltage form the DC-DC booster circuit is converted to three-phase PWM AC using three-phase inverter controlled by sinusoidal PWM technique [10] [11] [12]. To reduce harmonics in the PWM AC and make it sinusoidal AC for interconnection to the grid a LC filter is used.

The reference signals generated to operate the inverter are given as:

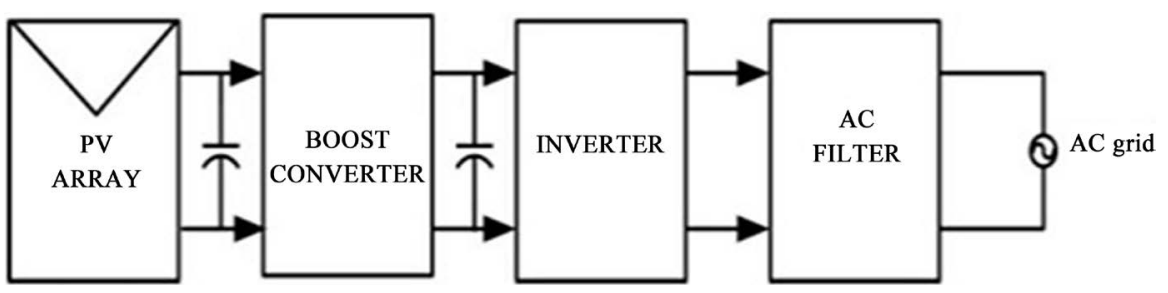

Figure 1. Considered test system block diagram. 


$$
\begin{aligned}
& V_{\text {aref }}=V_{m} \sin (w t) \\
& V_{\text {bref }}=V_{m} \sin (w t-2 \mathrm{pi} / 3) \\
& V_{\text {cref }}=V_{m} \sin (w t+2 \mathrm{pi} / 3)
\end{aligned}
$$

Here $V_{m}$ is the modulation index of the reference signal which can also be denoted as amplitude of the signal, $w$ is the angular frequency given as $2 \pi f(f$ is the fundamental frequency of the grid), $2 \mathrm{pi} / 3$ is the voltage phase difference of 120 degrees.

The $V_{m}$ and $w t$ variables are generated by the feedback PLL control with input from grid voltage. This paper includes the operation of the DC-DC booster converter with the voltage-oriented feedback controller in section II, followed by control of three-phase inverter with PLL in section III. Section IV includes simulation results followed by conclusion and references in section $\mathrm{V}$.

\section{DC-DC Booster Converter Design}

A DC-DC booster converter is utilized in applications which need higher voltage amplitude than the generated DC voltage amplitude. This converter is majorly integrated into renewable power generation units like PVAs, batteries, super capacitors, fuel cells, low voltage wind farms, etc. The voltage is increased to higher value to match with the required load voltage or grid voltage magnitude for a power injection in a normal operation condition. The DC-DC booster converter [13] [14] used in the test system can be seen below with the DC source input representing the PVA source.

Figure 2 has a single inductor (to store energy for boosting purpose) and a single capacitor for the reduction of ripples in the output voltage. Two power electronic devices, a diode to avoid reverse flow of current back to the source and a controllable MOSFET or IGBT switch (SW) [15] [16] used for controlling energy stored in the inductor. The only controllable device in the whole circuit is this switch which is controlled by a voltage-oriented feedback controller. The controller takes feedback from the output of the converter generating the duty ratio for the switch using a PI controller. The below Figure 3 is the control structure of the voltage-oriented feedback control system of the DC-DC booster converter.

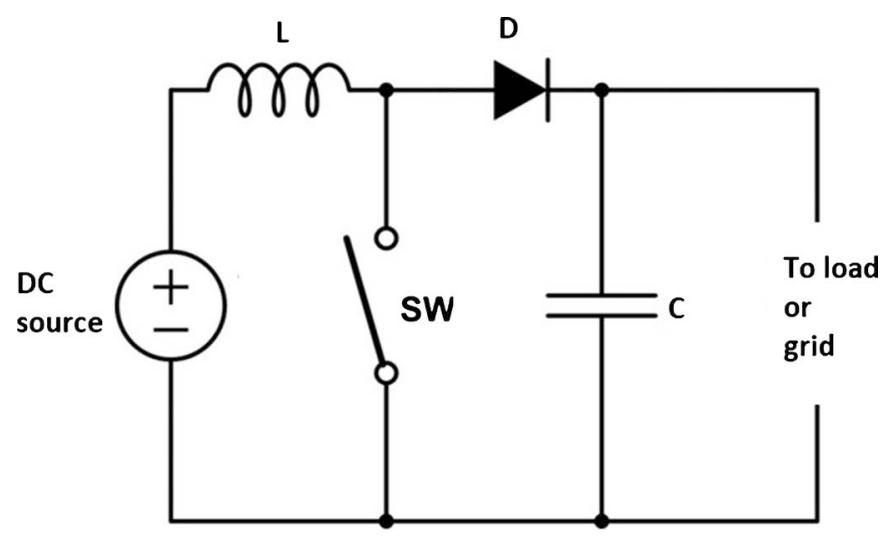

Figure 2. DC-DC booster converter circuit. 


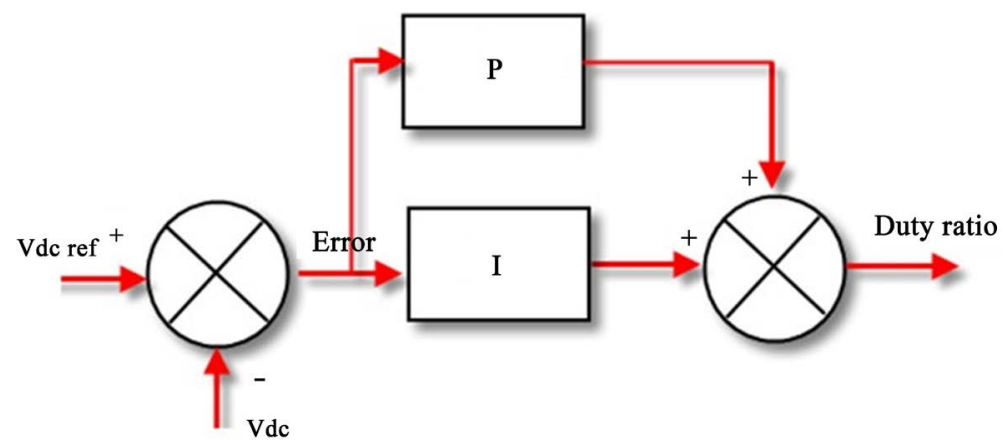

Figure 3. Voltage-oriented feedback controller for DC-DC booster converter.

The measured voltage $(\mathrm{Vdc})$ is compared to the reference required voltage (Vdc ref) generating an error fed to a PI (proportional and integral gain) controller. Certain values of $\mathrm{Kp}$ (proportional gain) and Ki (Integral gain) are generated by the trial and error method of the duty ratio [17] [18] for the switch and are compared to the high frequency triangular or saw tooth waveform for pulse generation. The pulse generated is fed to the switch controlling the output voltage of the DC-DC booster converter. The passive element ( $\mathrm{L}$ and $\mathrm{C}$ ) values of the converter are given as:

Minimum inductor size:

$$
L>\frac{V_{\text {in }} \cdot\left(V_{\text {out }}-V_{\text {in }}\right)}{\Delta I_{L} \cdot f_{s} \cdot V_{\text {out }}}
$$

Here $\Delta I_{L}$ is considered a ripple in the inductor current with a $10 \%$ ripple in the output current allowed is shown as:

$$
\Delta I_{L}=0.1 \times I_{\text {outmax }} \frac{V_{\text {out }}}{V_{\text {in }}}
$$

Here, $V_{\text {in }}$ is the input voltage, $V_{\text {out }}$ is the output voltage, $f_{s}$ is the switching frequency. The input voltage is considered as $400 \mathrm{~V}, V_{\text {out }}$ as $800 \mathrm{~V}, f_{s}$ as $5000 \mathrm{~Hz}$ and maximum output current $I_{\text {outmax }}$ to be $20 \mathrm{~A}$. The inductor value is calculated as:

$$
L=1 \mathrm{mH}
$$

The capacitor value is calculated as:

$$
C=\frac{I_{\text {outmax }} \cdot D}{f_{s} \cdot \Delta V_{\text {out }}}
$$

The output voltage ripple is given as:

$$
\Delta V_{\text {out }}=\operatorname{ESR}\left(\frac{I_{\text {outmax }}}{1-D}+\frac{\Delta I_{L}}{2}\right)
$$

Here, ESR is the series resistance of the capacitor, with the duty ratio considered as:

$0.5 \mathrm{ESR}$ as $0.05 \mathrm{ohms}$.

The output capacitor value is calculated as: 


$$
C=952 \mathrm{uF} \cong 1000 \mathrm{uF} .
$$

\section{Three-Phase Inverter Design}

The three-phase inverter comprises of six power electronic switches connected in a three-leg format. The power electronic switches used are IGBTs controlled by PWM signals [7] generated from the sinusoidal PWM technique. The reference sinusoidal signals for the PWM are generated by the PLL with feedback from the grid voltage [19] [20] [21]. The three-unit vector templates generated from the PLL are compared to a high frequency triangular waveform generating pulses for the IGBTs of the inverter [8] [9].

\section{PLL Design}

The phase-locked loop is a phase detection module used for measuring the grid voltage frequency and phase using the Park's transformation d-q reference frame locking the phase of the grid [10]. Orthogonally separated d-q reference frame signals are generated with a three-phase grid voltage input. During the grid voltage measurement, the signals contain small harmonics and disturbances which may distort the output. The signals are passed through low pass filters to reduce the disturbances and harmonics for a clear and smooth signal generation. The PLL is modelled using three units [22] [23] 1) phase detection unit 1) loop filter 3) voltage-controlled oscillator. The phase detection unit is Park's transformation for the generation of the $\mathrm{d}$-q reference frame for the given three-phase grid voltage input signals. The loop filter represents a PI controller with certain values of $\mathrm{Kp}$ and $\mathrm{Ki}$ used for reduction of disturbances in the d-q reference frame signals. The below Figure 4 is an internal block diagram of PLL with the Vabc input from the grid [13] [24].

The phase detector uses Clark's and Park's as shown in Figure 5 and Figure 6 respectively. Transformations for generation of the $\alpha$ - $\beta$ reference frame orthogonal signals. By applying Clark transformation, we get the equation [22]:

$$
\left[\begin{array}{c}
V_{\alpha} \\
V_{\beta} \\
V_{0}
\end{array}\right]=\left[\begin{array}{ccc}
1 & -\frac{1}{2} & -\frac{1}{2} \\
0 & \frac{\sqrt{3}}{2} & -\frac{\sqrt{3}}{2} \\
\frac{1}{2} & \frac{1}{2} & \frac{1}{2}
\end{array}\right]\left[\begin{array}{l}
V_{a} \\
V_{b} \\
V_{c}
\end{array}\right]
$$

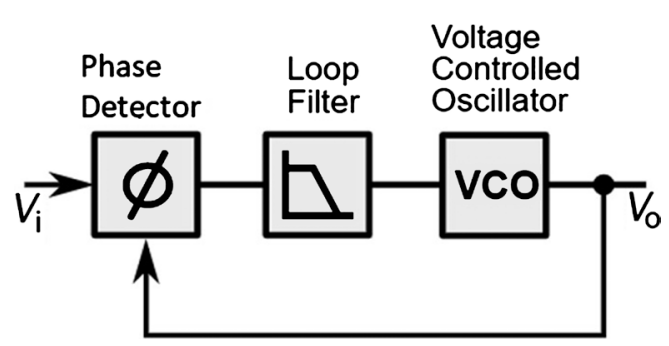

Figure 4. PLL internal modelling. 


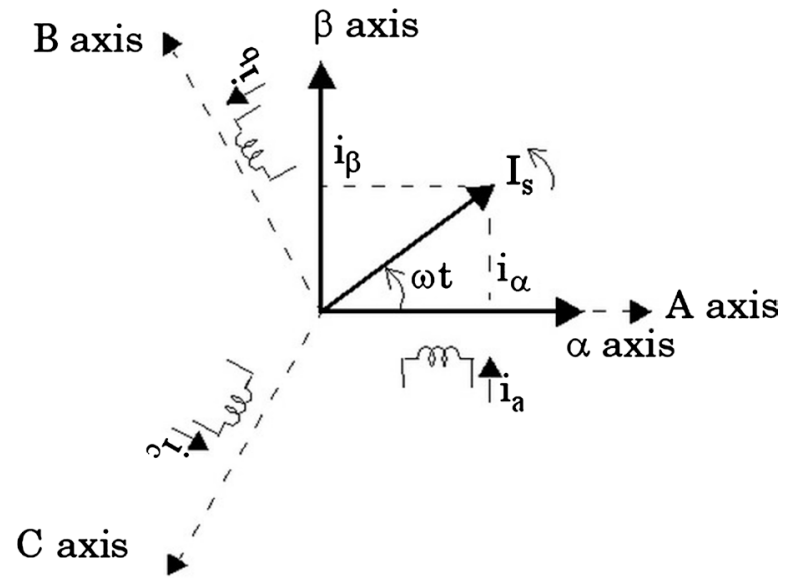

Figure 5. The Clark transformation.

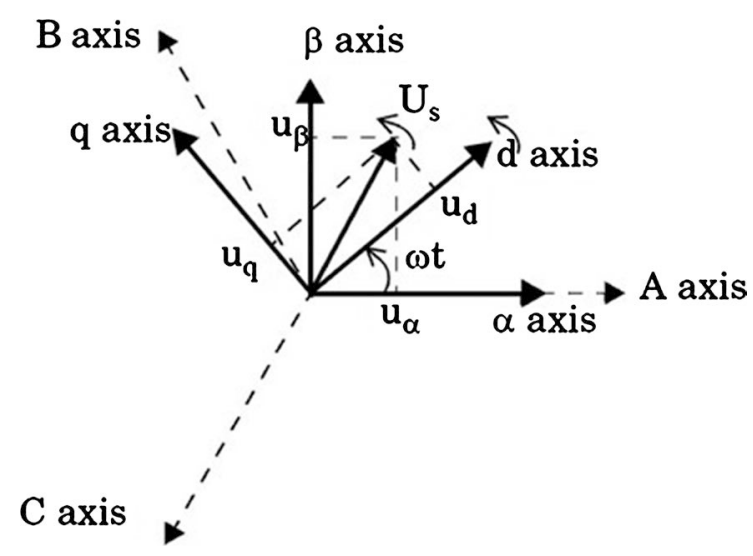

Figure 6. The Park transformation.

$$
\begin{aligned}
V_{\alpha} & =\left[V_{a}-\frac{V_{b}}{2}-\frac{V_{c}}{2}\right] \\
V_{\beta} & =\left[V_{b} \frac{\sqrt{3}}{2}-V_{c} \frac{\sqrt{3}}{2}\right] \\
V_{0} & =\left[V_{a}+\frac{V_{b}}{2}+\frac{V_{c}}{2}\right]
\end{aligned}
$$

By applying Park transformation, we get the equation [22]:

$$
\begin{aligned}
{\left[\begin{array}{l}
V_{d} \\
V_{q}
\end{array}\right] } & =\left[\begin{array}{cc}
\cos \theta_{e} & \sin \theta_{e} \\
-\sin \theta_{e} & \cos \theta_{e}
\end{array}\right]\left[\begin{array}{l}
V_{\alpha} \\
V_{\beta}
\end{array}\right] \\
V_{d} & =V_{\alpha} \cos \theta_{e}+V_{\beta} \sin \theta_{e} \\
V_{q} & =-V_{\alpha} \sin \theta_{e}+V_{\beta} \cos \theta_{e}
\end{aligned}
$$

The $V_{\alpha}$ and $V_{\beta}$ are the Clark's transformation rotating reference frame signals. After Park's transformation [22] from both the d-q frame orthogonal components only the q-axis component is considered and applied to a loop filter with a PI controller. The PI controller now generates the angular frequency $\omega$ added to the reference fundamental angular frequency $\omega_{\text {ref }}$ given as: 


$$
\omega_{\text {ref }}=2 \times \pi \times f_{n}
$$

Here, $f_{n}$ is the fundamental frequency of the grid voltage taken as $50 \mathrm{~Hz}$. The final angular frequency is fed to the integrator generating $\omega t$ reference for the generation of the reference unit vector templates given as:

$$
\begin{aligned}
& V_{a}=V_{m} \cos \omega t \\
& V_{b}=V_{m} \cos (\omega t+2 \pi / 3) \\
& V_{c}=V_{m} \cos (\omega t+4 \pi / 3)
\end{aligned}
$$

Here " $m$ " is the modulation index [24] [25] which changes the three-phase output voltage amplitude of the inverter. $2 \pi / 3$ is a 120 degrees phase shift between each phase in radians. The above generated unit vector templates are compared to high frequency triangular waveform generating pulses for the six switches in the inverter. To reduce the harmonics generated by the inverter, a three-phase LC filter is used. The LC filter design [8] is given below:

$$
L_{f}=\frac{2 \cdot V_{d c}}{2 \sqrt{2} \cdot \pi \cdot f_{s w} \cdot 3 \cdot \Delta I_{s}}
$$

Here $V_{d c}$ is the input voltage to the inverter, $f_{s w}$ is switching frequency of the inverter, $\Delta I_{s}$ is the considered ripple in the inductor current which is taken as $10 \%$. With the values given, the value of $L_{f}$ is calculated as $2 \mathrm{mH}$. With the given filter inductance value, the filter capacitance is given as:

$$
C_{f}=\frac{1}{4 \cdot f_{r}^{2} \cdot L_{f}}
$$

Here $f_{r}$ is the resonance frequency considered between:

$$
10 \cdot f_{\text {out }}<f_{r}<0.5 \cdot f_{\text {sw }}
$$

Therefore, the resonance frequency can be considered between $500 \mathrm{~Hz}$ to 5000 $\mathrm{Hz}$.

If a value of $501 \mathrm{~Hz}$ is taken the capacitance value is calculated as:

$$
C_{f}=500 \text {. }
$$

\section{Simulation Results}

The test system considered in section I is modelled in the Simulink environment of the MATLAB software shown below.

The above Figure 7 is the complete modelling of the proposed test system with the DC source connected to grid through the booster converter and threephase inverter with LC filter. All measurements are observed with power graphs and voltage graphs generated at each module as shown in Figure 8.

The simulation is run for 5 seconds and all the voltages, currents, and power of the modules are observed using graphical representation with respect to time.

The reference voltage is considered at $800 \mathrm{~V}$, compared to measured output voltage in Figure 9 of the converter generating duty ratio for the switch generating the nearest value of $780 \mathrm{~V}$. 


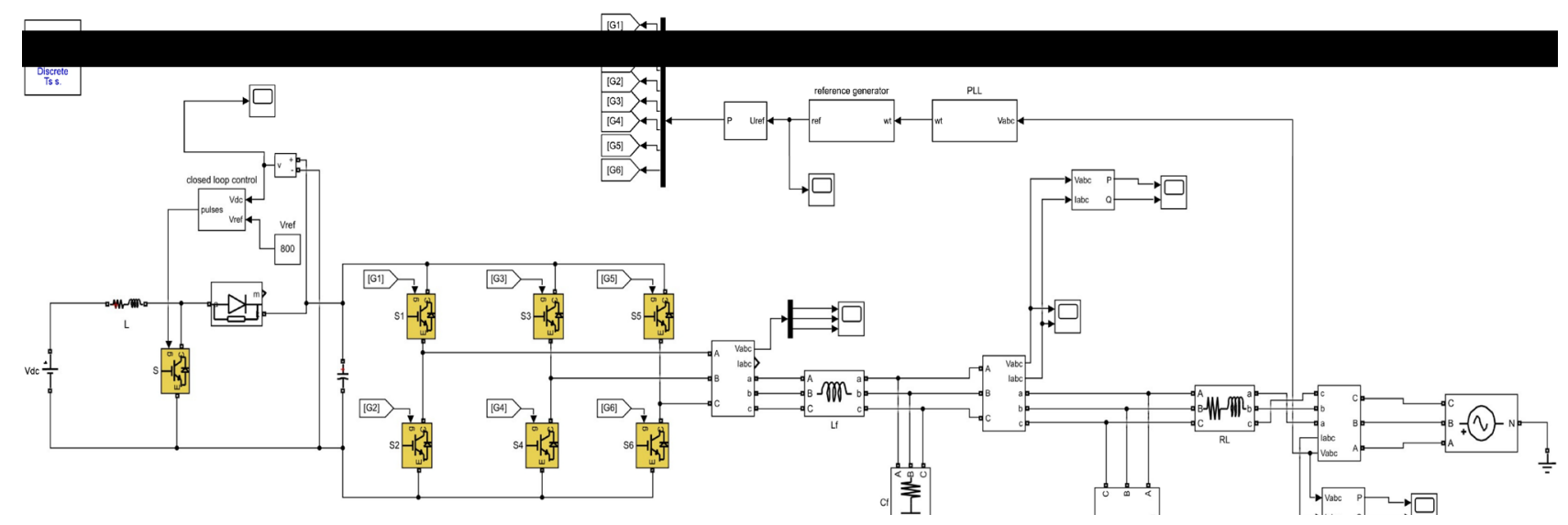

Figure 7. Simulation model of the test system.

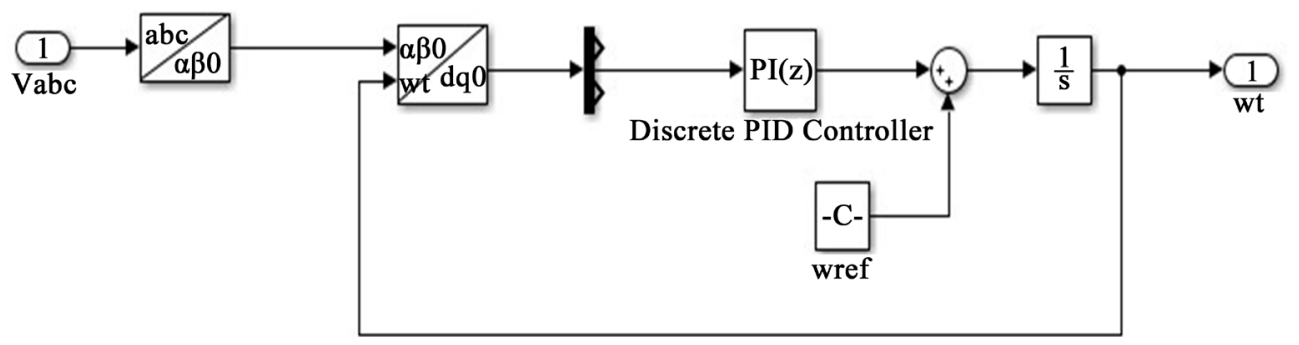

Figure 8. Simulation model of PLL (phase-locked loop).

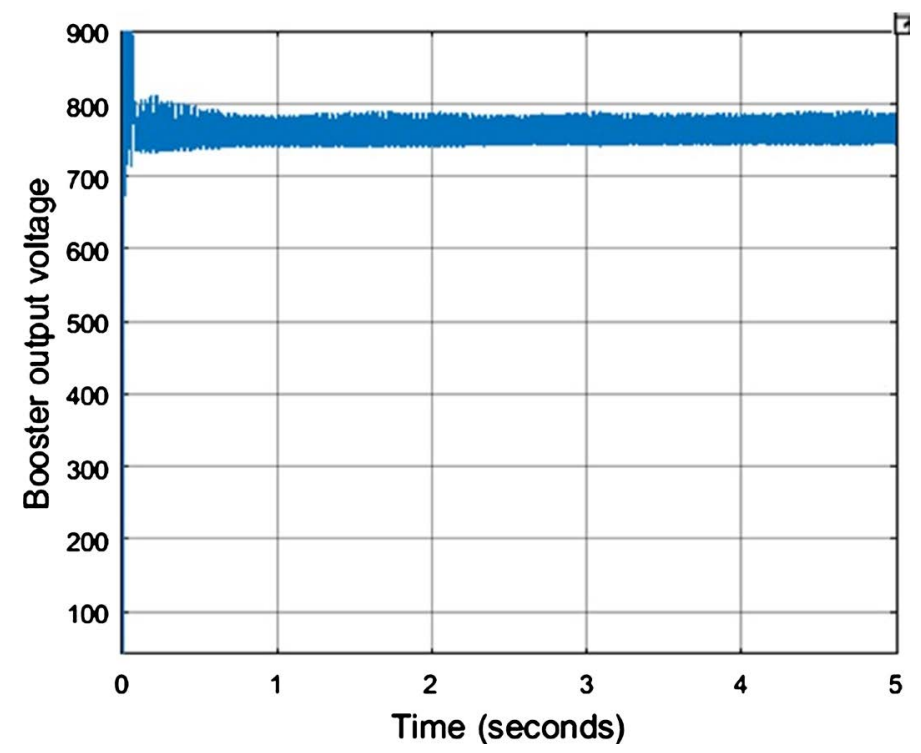

Figure 9. DC-DC booster output voltage. 
The above signals in Figure 10 are generated from the reference signal generated from the PLL.

The above Figure 11 and Figure 12 are the inverter voltages of three-phase and inverter voltages and currents respectively.

In the above graphs of Figure 13, the active power demand of the load is set at

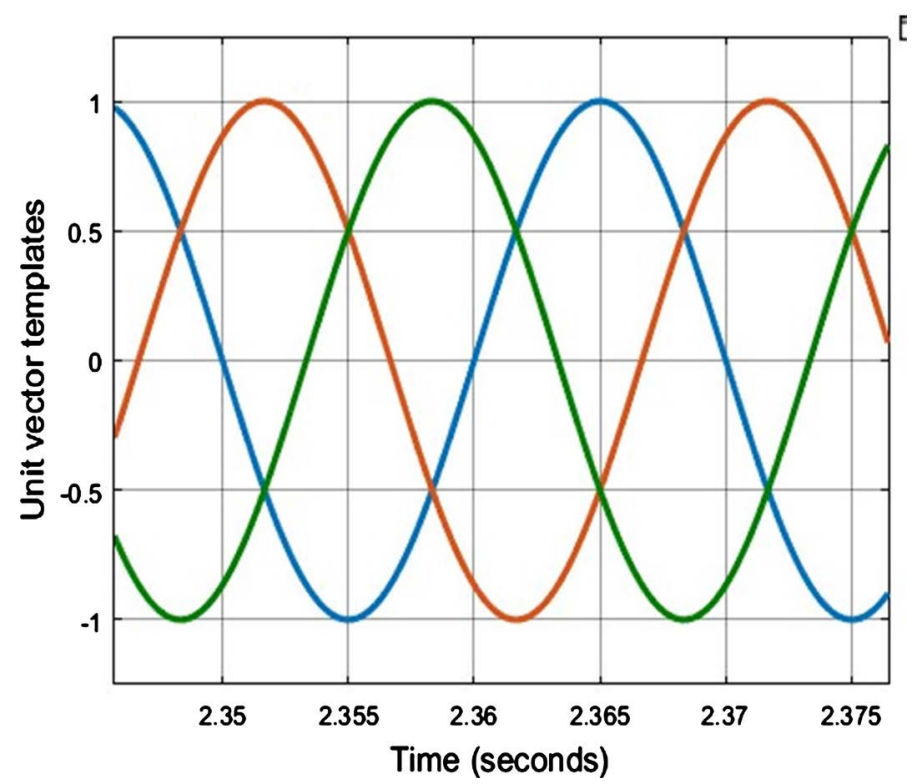

Figure 10. Reference unit vector templates for PWM pulse generation.
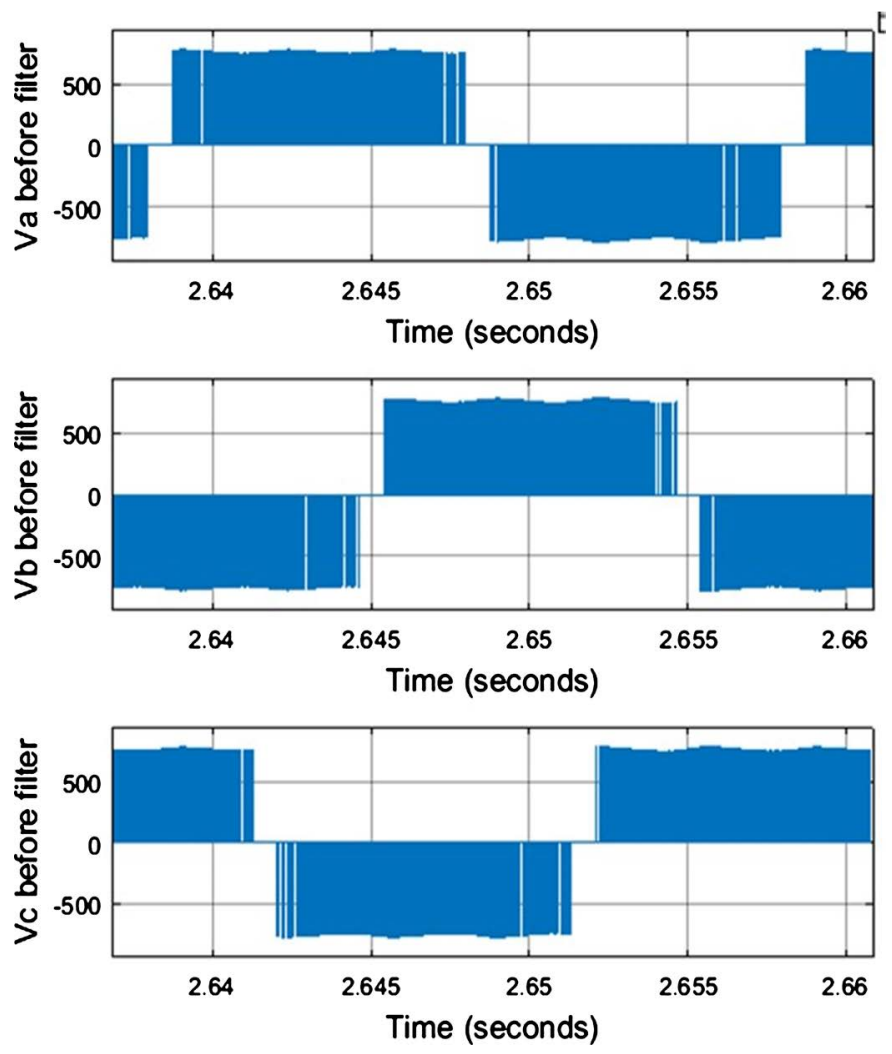

Figure 11. Three-phase PWM AC voltages. 

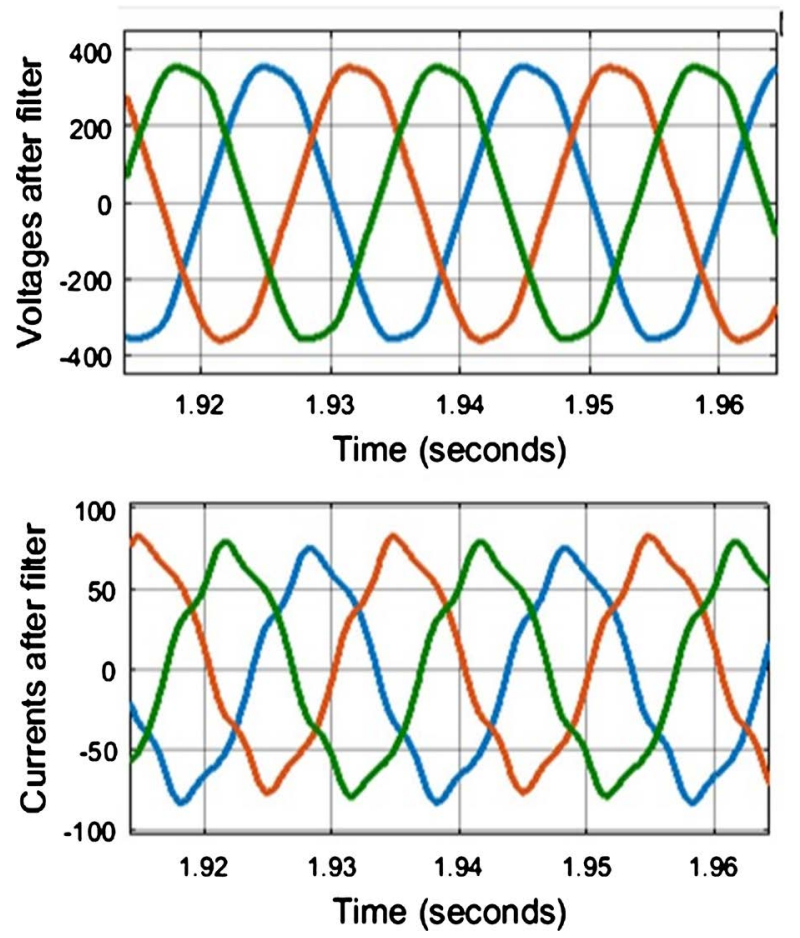

Figure 12. Three-phase voltages and current of inverter after LC filter.
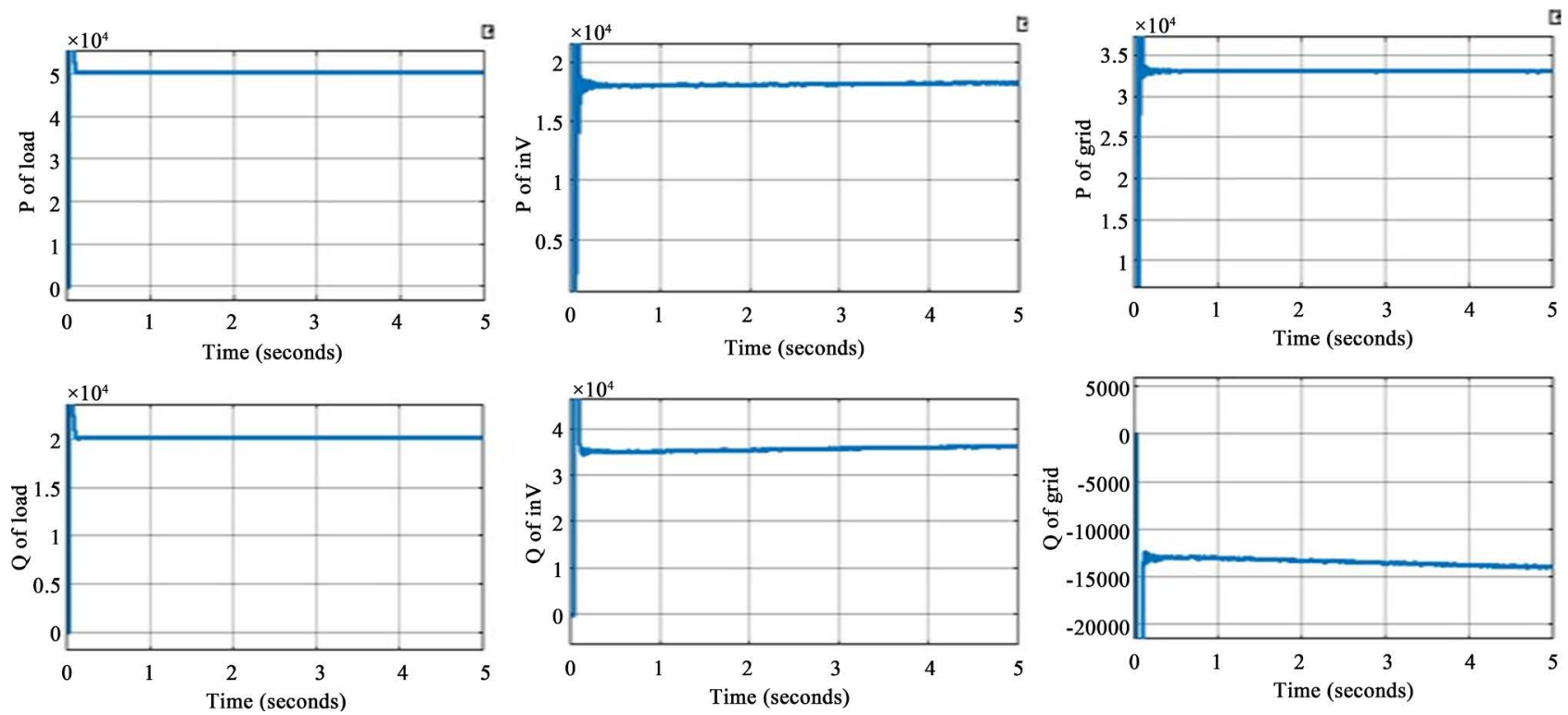

Figure 13. Active and reactive powers of load, inverter, and grid.

$50 \mathrm{~kW}$ and the reactive power demand is set at $20 \mathrm{kVAR}$. The inverter shares $\mathrm{P}$ of $18 \mathrm{~kW}$ and grid shares $32 \mathrm{~kW}$, whereas the inverter generates a more reactive power of $33 \mathrm{kVAR}$. The excess $\mathrm{Q}$ is injected into grid after compensating 20 $\mathrm{kVAR}$ of the load, hence reactive power of the grid is negative $13 \mathrm{kVAR}$ representing the grid. The below bar graph in Figure 14 is the inverter voltage THD analyzed using FFT analysis tool available in MATLAB's Power GUI block which also calculates the voltage magnitude. 


\section{Experimental Verification}

The above simulation model is verified with the experimental setup of $240 \mathrm{~W}$ power at the low-voltage grid connection of $24 \mathrm{Vrms}$. The battery pack used is a lithium ion battery with $12 \mathrm{~V} 20 \mathrm{Ahr}$ capacity. The battery is connected to a DC-DC booster converter to increase the voltage to peak value of $35 \mathrm{~V}$. The pulses for the booster converter and inverter are generated by the $\mathrm{D}$-Space system with the feedback from the grid voltage. The below Figure 15 is the prototype experimental setup of the proposed system.

The voltages and current of the grid and inverter are shown below.

As observed in Figure 16, the voltage of the grid and the inverter are syn-

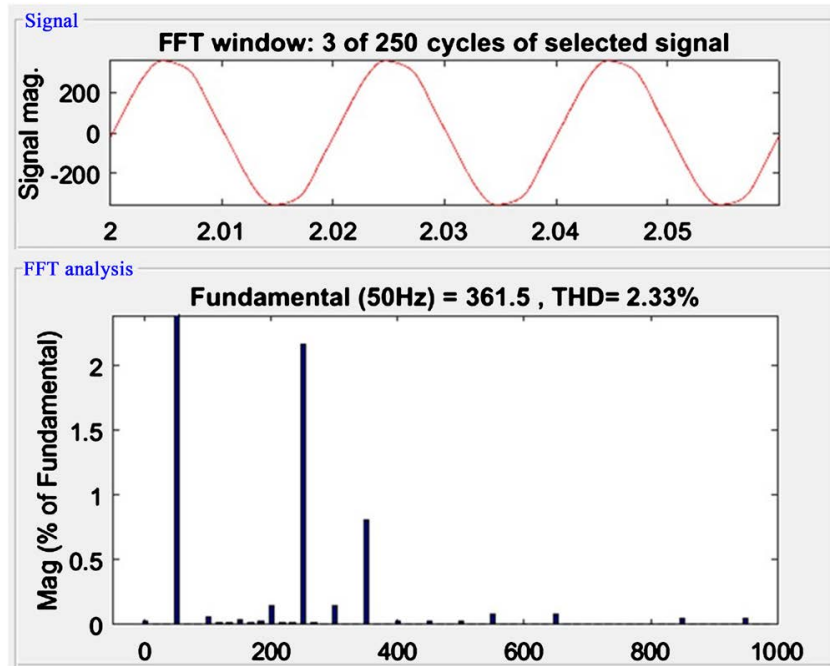

Figure 14. Inverter voltage THD.

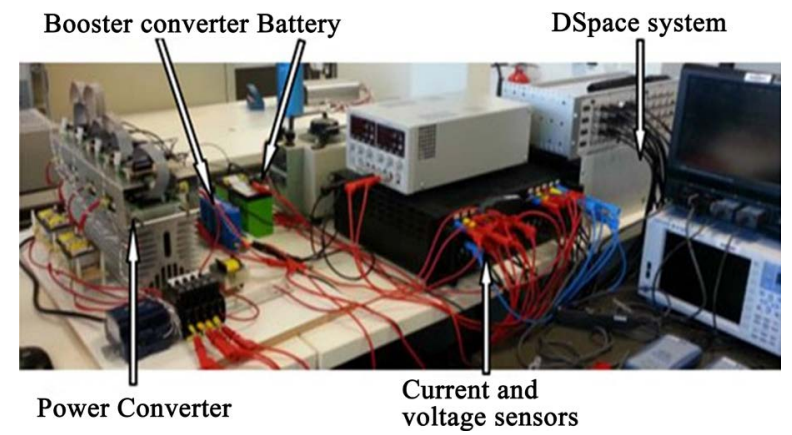

Figure 15. Prototype experimental setup.

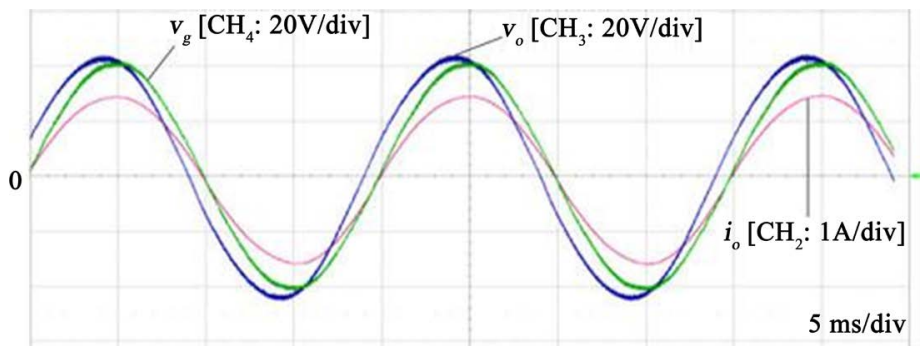

Figure 16. $V_{g}$ (grid voltage); $V_{o}$ (inverter voltage); $I_{o}$ (inverter current). 
chronized and power is shared by battery with the load parallel to the grid.

\section{Conclusion}

This paper presents the above modeling of the analysis of the test system of a DC source connected three-phase inverter interconnected to a grid through an LC filter. It can be proved that with grid synchronization using the PLL, the harmonics in the voltage can be maintained to a minimal value of $2.33 \%$. The power demanded by the load can be shared by both the sources in parallel without any disturbances in the grid voltage and currents. The maximum value of the single-phase voltage is noted at $361 \mathrm{~V}$ which is $255 \mathrm{Vrms}$ (allowable voltage $230 \% \pm$ $10 \%)$. The simulation is verified by a prototype experimental setup with the capacity of $240 \mathrm{~W}$ shared with the load connected parallel to the grid. The voltage and current graphs verify the synchronization of the battery connected to the grid through the inverter.

\section{Conflicts of Interest}

The authors declare no conflicts of interest regarding the publication of this paper.

\section{References}

[1] El-Tamaly, H.H., El-Tamaly, A.M. and El-Baset Mohammed, A.A. (2003) Design and Control Strategy of Utility Interfaced PV/WTG Hybrid System. The Ninth International Middle East Power System Conference, Vol. 2, 699-674.

https://www.researchgate.net/publication/236626970_Design_and_Control_Strateg y_of_Utility_Interfaced_PVWTG_Hybrid_System

[2] Alqarni, Z. and Asumadu, J.A. (2020) Synchronized Power Injection from PVA to Grid with Reduced THD and Dc Voltage Ripple Using PID Controller for Dc Grid Applications. 10th Annual Computing and Communication Workshop and Conference, Las Vegas, 6-8 January 2020, 248-256.

https://ieeexplore.ieee.org/stamp/stamp.jsp?arnumber=9031111 https://doi.org/10.1109/CCWC47524.2020.9031111

[3] Hansen, A.D., Sørensen, P., Hansen, L.H. and Bindner, H. (2000) Models for a Stand-Alone PV System. RIS National Laboratory, Roskilde. https://orbit.dtu.dk/files/7727175/ris_r_1219.pdf

[4] Omari, O., Ortjohann, E., Saiju, R., Hamsich, N. and Morton, D. (2003) A Simulation Model for Expandable Hybrid Power Systems. 2nd European PV-Hybrid and Mini-Grid Conference, Kassel, 25-26 September 2003, 377-382.

https://webcache.googleusercontent.com/search?q=cache:GInKtVx6PhMJ:https://w ww.aaup.edu/publication/osama.omari/conference-paper/simulation-model-expan dable-hybrid-power-systems $+\& \mathrm{~cd}=1 \& \mathrm{hl}=\mathrm{en} \& \mathrm{ct}=\mathrm{clnk} \& \mathrm{gl}=\mathrm{us}$

[5] El-Tamaly, H.H. and Elbaset Mohammed, A.A. (2008) Modeling and Simulation of Photovoltaic/Wind Hybrid Electric Power System Interconnected with Electrical Utility. 12th International Middle-East Power System Conference, Aswan, 12-15 March 2008, 645-649. https://ieeexplore.ieee.org/document/4562376 https://doi.org/10.1109/MEPCON.2008.4562376

[6] Barbosa, P.G., et al. (1995) Novel Control Strategy for Grid Connected DC/AC Converters with Load Power Factor and MPPT Control. Congresso Brasileiro de 
Eletrônica de Potência, Rio de Janeiro, April 1998, 363-371.

http://www.coe.ufrj.br/ rolim/papers/artigo.html

[7] Holtz, J. (1992) Pulse Width Modulation: A Survey. IEEE Transactions on Industrial Electronics, 39, 410-420. https://ieeexplore.ieee.org/document/161472 https://doi.org/10.1109/41.161472

[8] Onoe, Y., Kitagawa, W. and Takeshita, T. (2011) PWM Strategy of Bi-Directional Buck AC/DC Converter for Reducing Output Voltage Ripple. IEEE International Conference on Power Electronics and Drive Systems, Singapore, 5-8 December 2011, 256-261. https://ieeexplore.ieee.org/stamp/stamp.jsp?tp=\&arnumber $=7855373$ https://doi.org/10.1109/PEDS.2011.6147255

[9] Wang, C.-M. (2003) A Novel Single-Stage Full-Bridge Buck-Boost Inverter. Proceedings IEEE APEC 03, Miami Beach, 9-13 February 2003, 51-57. https://ieeexplore.ieee.org/stamp/stamp.jsp?arnumber $=1262063$

[10] Shimizu, T., Fujita, T., Kimura, G. and Hirose, J. (1997) A Unity Power Factor PWM Rectifier with DC Ripple Compensation. IEEE Transactions on Industrial Electronics, 44, 447-455. https://doi.org/10.1109/41.605618

https://ieeexplore.ieee.org/stamp/stamp.jsp?tp=\&arnumber $=605618$

[11] Jayasinghe, S.S.G., Vilathgamuwa, D.M. and Madawala, U.K. (2011) Diode-Clamped Three-Level Inverter-Based Battery/Supercapacitor Direct Integration Scheme for Renewable Energy Systems. IEEE Transactions on Power Electronics, 26, 3720-3729. https://doi.org/10.1109/TPEL.2011.2148178 https://ieeexplore.ieee.org/stamp/stamp.jsp?tp=\&arnumber $=5756696$

[12] Abeywardana, D.B.W., Hredzak, B. and Agelidis, V.G. (2013) An Integration Scheme for a Direct AC Line Battery-Supercapacitor Hybrid Energy Storage System. The Australasian Universities Power Engineering Conference, Hobart, 29 September-3 October 2013, 1-6. https://doi.org/10.1109/AUPEC.2013.6725474 https://ieeexplore.ieee.org/stamp/stamp.jsp?tp=\&arnumber $=6725474$

[13] Breucker, S.D. (2012) Impact of DC-DC Converters on Li-Ion Batteries. PhD Dissertation, Katholieke Universiteit Leuven, Leuven. https://limo.libis.be/primo-explore/fulldisplay?docid=LIRIAS1731034\&context=L\& $\underline{\text { vid=Lirias\&search_scope }=\text { Lirias\&tab }=\text { default_tab\&lang }=\text { en_US\&fromSitemap }=1}$

[14] Rodatz, P., Paganelli, G., Sciarretta, A. and Guzzella, L. (2005) Optimal Power Management of an Experimental Fuel Cell Supercapacitor-Powered Hybrid Vehicle. Control Engineering Practice, 13, 41-53.

https://www.sciencedirect.com/science/article/pii/S0967066103002910 https://doi.org/10.1016/j.conengprac.2003.12.016

[15] Caceres, R.O. and Barbi, I. (1999) A Boost DC-AC Converter: Analysis, Design, and Experimentation. IEEE Transactions on Power Electronics, 14, 134-141. https://ieeexplore.ieee.org/stamp/stamp.jsp?tp=\&arnumber=737601 https://doi.org/10.1109/63.737601

[16] Pierre-Olivier, M. and Claude, R. (2010) Partial AC-Coupling in Minigrids. 5 th European PV-Hybrid and Mini Grid Conference, Tarragona, 29-30 April 2010, 283-290. http://www-studer-innotec-com.www8.iomedia.infomaniak.ch/media/document/0/ partial_ac_coupling_in_minigrids.pdf

[17] Qian, H., Zhang, J., Lai, J. and Yu, W. (2011) A High-Efficiency Grid-Tie Battery Energy Storage System. IEEE Transactions on Power Electronics, 26, 886-896. https://ieeexplore.ieee.org/stamp/stamp.jsp?tp=\&arnumber $=5657267$ https://doi.org/10.1109/TPEL.2010.2096562

[18] Maharjan, L., Yamagishi, T. and Akagi, H. (2011) Active-Power Control of Indi- 
vidual Converter Cells for a Battery Energy Storage System Based on a Multilevel Cascade PWM Converter. IEEE Transactions on Power Electronics, 27, 1099-1107. https://ieeexplore.ieee.org/stamp/stamp.jsp?tp=\&arnumber $=5512647$ https://doi.org/10.1109/TPEL.2010.2059045

[19] Chanerjee, S. and Chanerjee, S. (2015) Simulation of Synchronous Reference Frame PLL Based Grid Connected Inverter for Photovoltaic Application. 1st Conference on Power, Dielectric and Energy Management at NERIST, Itanagar, 10-11 January 2015, 1-6. https://ieeexplore.iee.org/stamp/stamp.jsp?tp=\&arnumber=7084493 https://doi.org/10.1109/ICPDEN.2015.7084493

[20] Chen, M., Yao, W., Qian, Z.M., Gao, M.Z. and Li, B.H. (2009) Analysis and Implementation of a PLL Structure for Single-Phase Grid-Connected Inverter System. 6 th International Power Electronics and Motion Control Conference, Wuhan, 17-20 May 2009, 716-719.

https://ieeexplore.ieee.org/stamp/stamp.jsp?tp=\&arnumber $=5157478$

[21] Ferreira, R.J., Araujo, R.E. and Lopes, J.A.P. (2011) A Comparative Analysis and Implementation of Various PLL Techniques Applied to Single-Phase Grids. Proceedings 3 rd International Youth Conference on Energetics, Vol. 1, 1-8. https://ieeexplore.iee.org/stamp/stamp.jsp?tp=\&arnumber=6028325

[22] Zheng, C., F. Yuhong, and C. C. Mi, (2013) State of Charge Estimation of Lithiumion Batteries in Electric Drive Vehicles Using Extended Kalman Filtering. IEEE Transactions on Vehicular Technology, 62, 1020-1030.

https://ieeexplore.ieee.org/stamp/stamp.jsp?tp=\&arnumber $=6389785$ https://doi.org/10.1109/TVT.2012.2235474

[23] Tang, X., Mao, X., Lin, J. and Koch, B. (2011) Li-Ion Battery Parameter Estimation for State of Charge. Proceedings ACC, 29 June-1 July 2011, 941-946. https://ieeexplore.ieee.org/stamp/stamp.jsp?tp=\&arnumber $=5990963$

[24] Hosseinzadeh, M. and Salmasi, F.R. (2015) Robust Optimal Power Management System for a Hybrid AC/DC Micro-Grid. IEEE Transactions on Sustainable Energy, 6, 675-687. https://ieeexplore.iee.org/stamp/stamp.jsp?tp=\&arnumber=7076615 https://doi.org/10.1109/TVT.2012.2235474

[25] Ullah, M.H., Chalise, S. and Tonkoski, R. (2016) Feasibility Study of Energy Storage Technologies for Remote Microgrid's Energy Management Systems. International Symposium on Power Electronics, Electrical Drives, Automation and Motion, Anacapri, 22-24 June 2016, 689-694. https://doi.org/10.1109/SPEEDAM.2016.7525918 https://ieeexplore.ieee.org/stamp/stamp.jsp?tp=\&arnumber $=7525918$ 